\title{
Rectal cancer surgery in older people does not increase postoperative complications - a retrospective analysis
}

\author{
Jagdeep Singh ${ }^{1}$, Anton Stift', Sarah Brus ${ }^{1}$, Katharina Kosma ${ }^{1}$, Martina Mittlböck ${ }^{2}$ and Stefan Riss ${ }^{1 *}$
}

\begin{abstract}
Background: Rectal cancer surgery in the older population remains a highly controversial topic. The present study was designed to assess whether older patients had an increased risk for postoperative complications after rectal resection for malignancies.

Methods: Consecutive patients ( $n=627$ ), who underwent rectal cancer resection at a single institution, were included in the study and analyzed retrospectively. Short-term complications were compared between patients $\geq 80$ years $(n=55)$ and $<80$ years $(n=572)$. Additionally, predictive factors for postoperative complications were analyzed.

Results: The older aged group showed a significantly higher rate of co-morbidities compared to controls, in terms of cardiovascular and pulmonary diseases $(P=0.002, P=0.006)$. In older patients, a Hartmann's procedure and transanal endoscopic microsurgery (TEM) were performed most frequently $(P<0.0001)$.

The overall complication rate was 39\% ( $n=244)$ (medical: $n=59(9 \%)$, surgical: $n=185$ (30\%)), including 24 (44\%) complications in the older aged group (medical: $n=6(11 \%)$, surgical: $n=18(33 \%))$. Notably, the incidence of surgical and medical complications showed no significant difference between patients and controls $(P=0.58, P=0.69)$.

Neurological and cardiovascular disorders were associated with an increased risk for a eventful postoperative course in the older aged group $(P=0.03, P=0.04)$.
\end{abstract}

Conclusions: Rectal cancer resection can be performed safely in selected older patients. Age itself should not be considered as a risk factor for postoperative complications.

Keywords: Rectal cancer, Rectal surgery, Older patients, Risk factors, Postoperative complications

\section{Background}

Colorectal cancer is the third most common malignancy worldwide with an increasing incidence over the last decade, especially in the older population [1]. In the light of increasing life expectancy, the medical health system will be confronted with a significantly growing number of older patients in the upcoming years. This development will not only change our daily clinical routine but also challenge the decision-making in the treatment of malignancies in this generation. The careful assessment of the patients will become an essential and central issue

\footnotetext{
* Correspondence: stefan.riss@meduniwien.ac.at

${ }^{1}$ Department of Surgery, Medical University of Vienna, Währinger Gürtel

18-20, A-1090 Vienna, Austria

Full list of author information is available at the end of the article
}

and choosing the appropriate treatment for each patient will rely on a multidisciplinary process.

Older people often have a significant number of comorbidities, thus clinicians tend to offer less aggressive oncological treatment, with the potential consequences of early disease recurrence and reduced overall survival.

In the literature, the optimal treatment of rectal cancer in older aged patients remains controversial [2]. In addition, the interpretation of current data needs to be done with caution as most studies included both colonic and rectal cancer, although treatment strategies and morbidity rates vary significantly. Secondly, the definition of the older aged population is inconsistent with an age range of between 65 and 85 years.

Several studies have described that older age alone is not a risk factor for postoperative complications for 
patients with rectal cancer and therefore does not increase the mortality rate [3-7]. In contrast, other studies found out that increased age correlated with a higher postoperative mortality rate and lower overall survival [8-10]. Notably, the occurrence of co-morbidities influenced the mortality rate significantly $[3,11,12]$.

The present study was designed to evaluate whether older patients ( $>80$ years) have an increased risk for postoperative complications after rectal cancer surgery. In addition, we aimed to define parameters to predict an eventful postoperative course in this group of patients.

\section{Methods}

Between 1997 and 2010, 627 patients (female: $\mathrm{n}=248$ (40\%), male: $\mathrm{n}=379(60 \%)$, aged 18 to 92 years), who underwent rectal cancer resection at the Department of Surgery, Medical University of Vienna, were included in the study and analyzed retrospectively.

Rectal cancer surgery was divided into intersphincteric or complete rectal resection with coloanal anastomosis and low anterior resection with colorectal anastomosis. A transanal endoscopic microsurgery (TEM), a Hartmann's procedure or an abdominoperineal resection was conducted in selected cases.

The investigation was approved by the local ethics committee. Data were collected from the institutional colorectal database and individual chart reviews respectively.

Postoperative complications were defined as complications during the first 30 days after surgery and divided into surgical and medical. In addition, postoperative complications were graded according to the Clavien-Dindo classification [13].

Short-term complication rates were compared between patients $\geq 80$ years and controls ( $<80$ years).

In addition, 110 patients, 55 in each group, were selected for a matched pair analysis. The control group was matched by sex, type of neoadjuvant therapy and type of operation. Hereby, we aimed to achieve more accurate data, as radio/chemotherapy and the type of surgical procedure may also have an impact on the outcome.

Predictive factors for postoperative complications in older patients were analyzed: age, gender, smoking status, co-morbidities, tumor localization, tumor staging, UICC-criteria (Union Internationale Contre le Cancer), preoperative therapy and type of operation.

\section{Statistical analyses}

The chi-square test, the exact chi-square test and the Fisher's exact test were used to assess associations between categorical variables. In case of ordinal variables a trend version of the chi-square test was used. For matched data analyses the McNemar test was used for binary variables and a test of symmetry for nominal data. All $P$-values are two-sided and $P \leq 0.05$ was considered significant. All calculations were performed with the statistical analysis software SAS (SAS Institute Inc., Version 9.3, Cary, NC, USA).

\section{Results}

Patients ( $\geq 80$ years) and controls ( $<80$ years)

Demographic data of patients $\geq 80$ years and controls $(<80$ years) are outlined in Table 1.

The older aged group $(\mathrm{n}=55(9 \%))$ showed a significantly higher rate of co-morbidities compared to the control group. Especially, cardiovascular disease and pulmonary disease were observed more frequently in patients aged above 80 years $(P=0.002$ and $P=0.006)$. The most common pulmonary disease was chronic obstructive pulmonary disease (COPD) $(\mathrm{n}=6(11 \%))$. Furthermore, $319(56 \%)$ patients in the control group received neoadjuvant chemotherapy or radiotherapy compared to $18(33 \%)$ of older patients $(P=0.005)$.

Lower anterior resection was the most common operation in both groups. Notably, the older aged group received more TEMs and Hartmann's procedures ( $\mathrm{n}=8(14 \%)$ and $\mathrm{n}=7(13 \%)$ ) but fewer intersphincteric resections $(\mathrm{n}=1(2 \%))$ and low anterior resections $(\mathrm{n}=28(51 \%))$ compared to the control group ( $\mathrm{n}=14(3 \%), \mathrm{n}=15$ $(3 \%), \mathrm{n}=42(7 \%)$ and $\mathrm{n}=374(65 \%))(P<0.0001)$.

A total of 244 complications were observed in the present series. We found 24 (10\%) complications in the older aged group (surgical: $\mathrm{n}=18$ (33\%) and medical: $\mathrm{n}=6$ $(11 \%))$ and $220(38 \%)$ complications in the control group (surgical: $\mathrm{n}=167$ (29\%) and medical: $\mathrm{n}=53(9 \%)$ ). Most common surgical and medical complications were wound infections (older age: $\mathrm{n}=6$ (11\%), control: $\mathrm{n}=45(8 \%)$ ), paralytic ileus (older age: $\mathrm{n}=2(4 \%)$, control: $\mathrm{n}=33(6 \%)$ ), anastomotic leaks (older age: $\mathrm{n}=2(4 \%)$, control: $\mathrm{n}=26$ $(5 \%)$ ), urological complications (older age: $\mathrm{n}=4(7 \%)$, control: $\mathrm{n}=26(5 \%)$ ), cardiovascular complications (older age: $\mathrm{n}=2(4 \%)$, control: $\mathrm{n}=17(3 \%))$ and fever (older age: $\mathrm{n}=0$, control: $\mathrm{n}=16(3 \%))$. They are further outlined in Table 2 . Notably, no significant differences were detected between both groups $(P=0.58, P=0.69)$.

Additionally, no difference was observed between the older population and controls in regard to the ClavienDindo classification: in the older aged group, $6(11 \%)$ patients were classified as grade I, $8(15 \%)$ as grade II, $2(4 \%)$ as grade IIIa and $6(11 \%)$ as grade IIIb $(P=0.35)$. None of the older patients died in the perioperative period.

Regarding the control group, 63 (11\%) patients were classified as grade I, $55(10 \%)$ as grade II, $14(3 \%)$ as grade IIIa and $49(9 \%)$ as grade IIIb. Six (1\%) patients were classified as grade IV.

\section{Matched pair analysis}

Apart from the matching criteria (type of neoadjuvant therapy, type of operation and sex), the height of tumor, 
Table 1 Demographic data of patients ( $\geq 80$ years) and controls ( $<80$ years)

\begin{tabular}{|c|c|c|c|}
\hline & \multirow{2}{*}{$\begin{array}{l}\text { Group } 1 \\
\text { Age } \\
<80 \\
\text { years }\end{array}$} & \multirow{2}{*}{$\begin{array}{l}\text { Group } 2 \\
\text { Age } \\
\geq 80 \\
\text { years }\end{array}$} & \multirow[t]{3}{*}{$P$-value } \\
\hline & & & \\
\hline & $\mathrm{n}=572$ & $\mathrm{n}=55$ & \\
\hline Gender & & & 0.071 \\
\hline Female & $220(38)$ & $28(51)$ & \\
\hline Male & $352(62)$ & $27(49)$ & \\
\hline \multicolumn{4}{|l|}{ Co-morbidities } \\
\hline Cardiovascular diseases & $250(44)$ & $36(65)$ & 0.002 \\
\hline Pulmonary diseases & $63(11)$ & $13(24)$ & 0.006 \\
\hline Neurological diseases & $34(6)$ & $6(11)$ & 0.149 \\
\hline Diabetes mellitus & $84(15)$ & $9(16)$ & 0.738 \\
\hline Tumor localizations & & & 0.432 \\
\hline Upper rectum (12 to $16 \mathrm{~cm}$ ) & $107(19)$ & $7(13)$ & \\
\hline Middle rectum (6 to $12 \mathrm{~cm}$ ) & $220(39)$ & $25(46)$ & \\
\hline Lower rectum $(\leq 6 \mathrm{~cm})$ & $241(42)$ & $22(41)$ & \\
\hline UICC-criteria & & & 0.109 \\
\hline । & $174(31)$ & $21(41)$ & \\
\hline$\|$ & $117(21)$ & $10(20)$ & \\
\hline III & $156(28)$ & $14(27)$ & \\
\hline IV & $109(20)$ & $6(12)$ & \\
\hline Operative access & & & 0.0004 \\
\hline Open & $511(90)$ & $44(80)$ & \\
\hline Laparoscopic & $44(7)$ & $3(5)$ & \\
\hline Transanal & $15(3)$ & $8(15)$ & \\
\hline Operation techniques & & & $<0.0001$ \\
\hline Low anterior resection & $374(65)$ & $28(51)$ & \\
\hline Rectum extirpation & $65(11)$ & $6(11)$ & \\
\hline Intersphincteric resection & $42(7)$ & $1(2)$ & \\
\hline Transanal endoscopic microsurgery & $14(3)$ & $8(14)$ & \\
\hline Hartmann's procedure & $15(3)$ & $7(13)$ & \\
\hline Complete rectal resection & $48(8)$ & $4(7)$ & \\
\hline Others & $14(3)$ & $1(2)$ & \\
\hline Stomas & & & 0.024 \\
\hline Colostoma & $121(21)$ & $18(33)$ & \\
\hline Ileostoma & $259(45)$ & $15(27)$ & \\
\hline No stoma & $190(33)$ & $22(40)$ & \\
\hline Preoperative therapies & & & 0.005 \\
\hline No therapy & $253(44)$ & $37(67)$ & \\
\hline Chemo or radio/chemotherapy & $125(22)$ & $7(13)$ & \\
\hline Radiotherapy & $194(44)$ & $11(20)$ & \\
\hline
\end{tabular}

Values are given as numbers and absolute frequencies (\%).
Table 2 Surgical and medical complications between patients ( $\geq 80$ years) and controls ( $<80$ years)

\begin{tabular}{|c|c|c|c|}
\hline & \multirow{2}{*}{$\begin{array}{l}\text { Group } 1 \\
\text { Age } \\
<80 \\
\text { years }\end{array}$} & \multirow{2}{*}{$\begin{array}{l}\text { Group } 2 \\
\text { Age } \\
\geq 80 \\
\text { years }\end{array}$} & \multirow[t]{3}{*}{$P$-value } \\
\hline & & & \\
\hline & n (\%) & n (\%) & \\
\hline Surgical complications & $167(29)$ & $18(33)$ & 0.583 \\
\hline Anastomotic leakage & $26(5)$ & $2(4)$ & \\
\hline Wound infection & $45(8)$ & $6(11)$ & \\
\hline Bleeding & $6(1)$ & 0 & \\
\hline Paralytic ileus & $33(6)$ & $2(4)$ & \\
\hline Mechanical obstruction & $4(1)$ & 0 & \\
\hline Blood transfusion & $7(1)$ & $1(2)$ & \\
\hline Intraabdominal abscess & $6(1)$ & 0 & \\
\hline Urological complications & $26(5)$ & $4(7)$ & \\
\hline Others & $14(3)$ & $3(6)$ & \\
\hline Medical complications & $53(9)$ & $6(11)$ & 0.690 \\
\hline Fever & $16(3)$ & 0 & \\
\hline Thrombosis & $3(1)$ & 0 & \\
\hline Pulmonary embolism & $5(1)$ & 0 & \\
\hline Cardiovascular complications & $17(3)$ & $2(4)$ & \\
\hline Pneumonia & $2(0)$ & $1(2)$ & \\
\hline Others & $10(2)$ & $3(6)$ & \\
\hline
\end{tabular}

tumor stage and the number of stoma creations were equally distributed between both groups. However, in the older aged group $13(24 \%)$ patients presented with pulmonary diseases compared to $2(4 \%)$ patients in the control group $(P=0.005)$.

The overall complication rate in the older aged group was $40 \%(\mathrm{n}=22)$ and $31 \%(\mathrm{n}=17)$ in the control group ( $P=0.34$ ). In addition, no difference was found between the older aged and control group in regard to surgical $(\mathrm{n}=18(33 \%)$ and $\mathrm{n}=12(22 \%))$ and medical complications $(\mathrm{n}=6(11 \%)$ and $\mathrm{n}=6(11 \%))(P=0.18$ and $P=1.0)$. According to the Clavien-Dindo classification no significant difference was observed either $(P=0.95)$ (Table 3$)$.

\section{Risk factors for postoperative complications in older patients}

Neurological and cardiovascular diseases correlated with an increased risk for a postoperative eventful course within 30 days post-surgery. Five out of 6 patients with a neurological disease $(83 \%)$ had postoperative complications within 30 days, compared to only $35 \%$ of the patients without a neurological disease (17 of 49 patients; $P=0.033)$. Half of the patients with a cardiovascular disease (18 of 36), but only $21 \%$ of the patients without a cardiovascular disease ( 4 of 19 patients; $P=0.037$ ), developed 
Table 3 Clavien-Dindo classification of patients and matched controls

\begin{tabular}{|c|c|c|c|}
\hline & $\begin{array}{l}\text { Match group } 1 \\
\text { Age }<80 \text { years } \\
\text { (\%) }\end{array}$ & $\begin{array}{l}\text { Match group } 2 \\
\text { Age } \geq 80 \text { years } \\
n(\%)\end{array}$ & $P$-value \\
\hline $\begin{array}{l}\text { Patients without } \\
\text { complications }\end{array}$ & $39(71)$ & $33(60)$ & \\
\hline Clavien-Dindo grade & & & 0.953 \\
\hline । & $4(7)$ & $6(11)$ & \\
\hline$\|$ & $5(9)$ & $8(15)$ & \\
\hline Illa & $1(2)$ & $2(4)$ & \\
\hline$\| l l b$ & $5(9)$ & $6(11)$ & \\
\hline IV to $\mathrm{V}$ & $1(2)$ & 0 & \\
\hline
\end{tabular}

Values are given as numbers and absolute frequencies (\%).

postoperative complications. The detailed list of risk factors is shown in Table 4.

In addition, the type of anastomotic configurations had a significant impact on postoperative medical complications $(P=0.048)$. However, a J-pouch was performed in only one patient, who afterwards developed a medical complication.

\section{Discussion}

In the present analysis we could clearly demonstrate that rectal cancer resections can be conducted safely in selected older patients without an increased number of postoperative complications.

Surgery remains the only curative treatment for patients with rectal cancer [14]. However, no clear guidelines for a standardized management in older patients with colorectal cancer exist so far. Most available studies included older patient cohorts aged between 65 and 75 years, with only a paucity of studies investigating the outcome after rectal resections in patients over 80 years $[3,4,10,11,15,16]$.

Previous studies showed that colorectal surgery did not impair postoperative outcomes in older patients $[3,11,15]$. However, most of these studies comprised patients with both colon and rectal cancer. We analyzed patients with rectal cancer only and measured comparable numbers of medical and surgical complications. In 2006, Law et al. analyzed postoperative events in patients over 75 years compared with younger patients undergoing rectal surgery. Altogether, $37 \%$ of the patients in the older aged group had complications and 30\% of the younger patients, leading to the conclusion that curative resection for rectal cancer could be performed safely in both age groups [11]. Vironen et al. assessed patients older than 75 years and found similar results in terms of complications after surgery [4].

Shahir et al. investigated treatment-related complications and overall survival in patients from the age of
60 years. The authors reported complication rates of $65 \%$ in patients $>70$ years and $51 \%$ in patients between 60 and 69 years. The older aged group was found to have more cardiac complications ( 8 versus $2 \%$ ) and pneumonia (12 versus 7\%) compared to younger controls. Furthermore, patients, who underwent surgery and received radiotherapy, had a significantly higher risk for postoperative complications than those undergoing surgery alone. Notably, in their series, the occurrence of complications was associated with an increase in the overall mortality rate [16]. In our series, none of the patients, who developed postoperative complications died during the observational period.

Few studies described older age as an independent risk factor for complications $[17,18]$. We analyzed predictive factors for a postoperative eventful course in older patients too and found only cardiovascular and neurological diseases to be correlated with a higher risk for postoperative short-term complications. Law et al. obtained similar results, showing that cardiovascular and neurological diseases occurred more frequently in the older patients. Turrentine et al. investigated the morbidity and mortality rates and risk factors in older patients undergoing major operations [18]. Hypertension and dyspnea were significantly associated with an eventful postoperative course.

It is worth mentioning that a higher rate of Hartmann's procedures was performed in the older aged group. Similar results were shown by Jung et al., where a total of $17 \%$ of the older patients received a Hartmann's procedure in contrast to $5 \%$ of the younger patients [10]. Older patients who are fit for surgery often complain about a reduced anorectal function. In those patients a primary low anastomosis might cause postoperative fecal incontinence and subsequently deteriorate quality of life; thus, a definitive stoma might be a better option in the long term. Additionally, a Hartmann's procedure has a shorter operative time and avoids possible anastomotic leakages with potential further interventions $[19,20]$.

The benefits of neoadjuvant radio/chemotherapy in rectal cancer treatment are well documented in the literature $[21,22]$. However, the Stockholm I and II trials have shown the distinct negative effects of neoadjuvant radiotherapy in older patients ( $<80$ years) [23-25]. The incidence of venous thromboembolism, femoral neck and pelvic fractures, intestinal obstruction and postoperative fistulas was significantly increased after preoperative radiotherapy in this group of patients [24]. Thus, a careful selection to choose the appropriate patients for neoadjuvant therapy is mandatory. In our series, older patients received preoperative treatment less frequently compared to younger patients.

Few limitations of the present study need to be addressed. The study was designed retrospectively, thus a 
Table 4 Risk factors for postoperative complications

\begin{tabular}{|c|c|c|c|}
\hline & $\begin{array}{l}\text { Complications } \\
\text { No }\end{array}$ & $\begin{array}{l}\text { Complications } \\
\text { Yes }\end{array}$ & $P$-value \\
\hline Gender & & & 0.920 \\
\hline Female & $17(61)$ & $11(39)$ & \\
\hline Male & $16(59)$ & $11(41)$ & \\
\hline UICC-criteria & & & 0.114 \\
\hline 1 & $16(76)$ & $5(24)$ & \\
\hline$\|$ & $5(50)$ & $5(50)$ & \\
\hline III & $7(50)$ & $7(50)$ & \\
\hline IV & $3(50)$ & $3(50)$ & \\
\hline Preoperative therapy & & & 0.591 \\
\hline No therapy & $24(65)$ & $13(35)$ & \\
\hline $\begin{array}{l}\text { Chemo or radio/ } \\
\text { chemotherapy }\end{array}$ & $4(57)$ & $3(43)$ & \\
\hline Radiotherapy & $5(45$ & $6(55)$ & \\
\hline Tumor localization & & & 0.839 \\
\hline $\begin{array}{l}\text { Upper rectum } \\
(12 \text { to } 16 \mathrm{~cm})\end{array}$ & $4(57)$ & $3(43)$ & \\
\hline Middle rectum (6 to $12 \mathrm{~cm}$ ) & $15(60)$ & $10(40)$ & \\
\hline Lower rectum $(\leq 6 \mathrm{~cm})$ & $14(63)$ & $8(36)$ & \\
\hline Operative access & & & 0.024 \\
\hline Open & $24(55)$ & $20(45)$ & \\
\hline Laparoscopic & $1(33)$ & $2(67)$ & \\
\hline Transanal & $8(100)$ & 0 & \\
\hline Operation technique & & & 0.126 \\
\hline Low anterior resection & $14(50)$ & $14(50)$ & \\
\hline Rectum extirpation & $3(50)$ & $3(50)$ & \\
\hline Intersphincteric resection & $1(100)$ & 0 & \\
\hline $\begin{array}{l}\text { Transanal endoscopic } \\
\text { microsurgery }\end{array}$ & $8(100)$ & 0 & \\
\hline Hartmann's procedure & $3(43)$ & $4(57)$ & \\
\hline Complete rectal resection & $3(75)$ & $1(25)$ & \\
\hline Others & $1(100)$ & 0 & \\
\hline Anastomotic technique & & & 0.354 \\
\hline No anastomosis & $12(63)$ & $7(37)$ & \\
\hline Staple & $15(52)$ & $14(48)$ & \\
\hline Manual & $5(83)$ & $1(17)$ & \\
\hline Anastomotic form & & & 0.500 \\
\hline No anastomosis & $12(63)$ & $7(37)$ & \\
\hline J-pouch & 0 & $1(100)$ & \\
\hline End-to-side anastomosis & $1(33)$ & $2(67)$ & \\
\hline End-to-end anastomosis & $20(63)$ & $12(37)$ & \\
\hline Stomas & & & 0.645 \\
\hline Colostoma & $10(56)$ & $8(44)$ & \\
\hline Ileostoma & $8(53)$ & $7(47)$ & \\
\hline None & $15(68)$ & $7(32)$ & \\
\hline
\end{tabular}

Table 4 Risk factors for postoperative complications

(Continued)

\begin{tabular}{|c|c|c|c|}
\hline Accessory surgery & & & 0.253 \\
\hline None & $23(66)$ & $12(34)$ & \\
\hline Accessory surgery & $10(50)$ & $10(50)$ & \\
\hline Neurological diseases & & & 0.033 \\
\hline No & $32(65)$ & $17(35)$ & \\
\hline Yes & $1(17)$ & $5(83)$ & \\
\hline Cardiovascular diseases & & & 0.037 \\
\hline No & $15(79)$ & $4(21)$ & \\
\hline Yes & $18(50)$ & $18(50)$ & \\
\hline Diabetes mellitus & & & 0.289 \\
\hline No & $26(57)$ & $20(43)$ & \\
\hline Yes & $7(78)$ & $2(22)$ & \\
\hline Pulmonary diseases & & & 0.244 \\
\hline No & $27(64)$ & $15(36)$ & \\
\hline Yes & $6(46)$ & $7(54)$ & \\
\hline Smoker & & & 0.760 \\
\hline No & $26(60)$ & $17(40)$ & \\
\hline Yes & $1(33)$ & $2(67)$ & \\
\hline No longer & $6(67)$ & $3(33)$ & \\
\hline
\end{tabular}

Values are given as numbers and absolute frequencies (\%).

selection bias cannot be ruled out. However, the active policy in our institution is to offer surgical treatment to the vast majority of older people who are referred to our clinic. Certainly, it is possible that few patients with rectal cancer were not seen by surgeons, as they were considered to be too frail to undergo surgery primarily, thus a conservative approach was chosen instead.

\section{Conclusions}

Rectal cancer resection can be performed safely in selected older patients. Age itself should not be considered as a risk factor for postoperative complications. Attention should be paid to neurological and cardiovascular diseases, as they may increase the risk for an eventful postoperative course.

\section{Abbreviations}

TEM: Transanal endoscopic microsurgery; UICC: Union internationale contre le cancer.

\section{Competing interests}

There were no conflicts of interest, sources of financial support, corporate involvement, patent holdings, and so on involved in the research and preparation of this manuscript.

\section{Authors' contributions}

$J S, A S, S B, K K, M M$ and SR contributed to conception, design, acquisition and interpretation of data. All authors revised the article and approved the final version. 


\section{Author details}

${ }^{1}$ Department of Surgery, Medical University of Vienna, Währinger Gürtel 18-20, A-1090 Vienna, Austria. ${ }^{2}$ Center for Medical Statistics, Informatics and Intelligent Systems, Medical University of Vienna, Vienna, Austria.

Received: 25 August 2014 Accepted: 6 November 2014 Published: 23 November 2014

\section{References}

1. Haraldsdottir S, Einarsdottir HM, Smaradottir A, Gunnlaugsson A, Halfdanarson TR: Colorectal cancer - review. Laeknabladid 2014, 100:75-82.

2. Pallis AG, Mouzas IA: Adjuvant chemotherapy for colon cancer. Anticancer Res 2006, 26:4809-4815.

3. Bufalari A, Giustozzi G, Burattini MF, Servili S, Bussotti C, Lucaroni E, Ricci E, Sciannameo F: Rectal cancer surgery in the elderly: a multivariate analysis of outcome risk factors. J Surg Oncol 2006, 93:173-180.

4. Vironen $\mathrm{JH}$, Sainio P, Husa Al, Kellokumpu IH: Complications and survival after surgery for rectal cancer in patients younger than and aged 75 years or older. Dis Colon Rectum 2004, 47:1225-1231.

5. Chiappa A, Zbar AP, Bertani E, Biella F, Audisio RA, Staudacher C: Surgical outcomes for colorectal cancer patients including the elderly. Hepatogastroenterology 2001, 48:440-444.

6. Puig-La Calle J Jr, Quayle J, Thaler HT, Shi W, Paty PB, Quan SH, Cohen AM, Guillem JG: Favorable short-term and long-term outcome after elective radical rectal cancer resection in patients 75 years of age or older. Dis Colon Rectum 2000, 43:1704-1709.

7. Makela JT, Kiviniemi H, Laitinen S: Survival after operations for colorectal cancer in patients aged 75 years or over. Eur J Surg 2000, 166:473-479.

8. Finlayson EV, Birkmeyer JD: Operative mortality with elective surgery in older adults. Eff Clin Pract 2001, 4:172-177.

9. Tan KK, Koh FH, Tan YY, Liu JZ, Sim R: Long-term outcome following surgery for colorectal cancers in octogenarians: a single institution's experience of 204 patients. J Gastrointest Surg 2012, 16:1029-1036.

10. Jung B, Pahlman L, Johansson R, Nilsson E: Rectal cancer treatment and outcome in the elderly: an audit based on the Swedish Rectal Cancer Registry 1995-2004. BMC Cancer 2009, 9:68.

11. Law WL, Choi HK, Ho JW, Lee YM, Seto CL: Outcomes of surgery for mid and distal rectal cancer in the elderly. World J Surg 2006, 30:598-604.

12. Barrier A, Ferro L, Houry S, Lacaine F, Huquier M: Rectal cancer surgery in patients more than 80 years of age. Am J Surg 2003, 185:54-57.

13. Dindo D, Demartines N, Clavien PA: Classification of surgical complications: a new proposal with evaluation in a cohort of 6336 patients and results of a survey. Ann Surg 2004, 240:205-213.

14. Chang GJ, Skibber JM, Feig BW, Rodriguez-Bigas M: Are we undertreating rectal cancer in the elderly? An epidemiologic study. Ann Surg 2007, 246:215-221.

15. Hotta T, Takifuji K, Yokoyama S, Matsuda K, Higashiguchi T, Tominaga T, Oku Y, Nasu T, Yamaue H: Rectal cancer surgery in the elderly: analysis of consecutive 158 patients with stage III rectal cancer. Langenbecks Arch Surg 2007, 392:549-558.

16. Shahir MA, Lemmens VE, Van de Poll-Franse LV, Voogd AC, Martijn H, Janssen-Heijnen ML: Elderly patients with rectal cancer have a higher risk of treatment-related complications and a poorer prognosis than younger patients: a population-based study. Eur J Cancer 2006, 42:3015-3021.

17. Edna TH, Bjerkeset T: Colorectal cancer in patients over 80 years of age. Hepatogastroenterology 1998, 45:2142-2145.

18. Turrentine FE, Wang H, Simpson VB, Jones RS: Surgical risk factors, morbidity, and mortality in elderly patients. J Am Coll Surg 2006, 203:865-877.

19. David GG, Al-Sarira AA, Willmott S, Cade D, Corless DJ, Slavin JP: Use of Hartmann's procedure in England. Colorectal Dis 2009, 11:308-312.

20. Adams WJ, Mann LJ, Bokey EL, Chapuis PH, Koorey SG, Hughes WJ: Hartmann's procedure for carcinoma of the rectum and sigmoid colon. Aust N Z J Surg 1992, 62:200-203.

21. De Caluwe L, Van Nieuwenhove Y, Ceelen WP: Preoperative chemoradiation versus radiation alone for stage II and III resectable rectal cancer. Cochrane Database Syst Rev 2013, 2:CD006041.

22. Wong RK, Tandan V, De Silva S, Figueredo A: Pre-operative radiotherapy and curative surgery for the management of localized rectal carcinoma. Cochrane Database Syst Rev 2007, 2:CD002102.
23. Holm T, Rutqvist LE, Johansson $\mathrm{H}$, Cedermark B: Postoperative mortality in rectal cancer treated with or without preoperative radiotherapy: causes and risk factors. Br J Surg 1996, 83:964-968.

24. Holm T, Singnomklao T, Rutqvist LE, Cedermark B: Adjuvant preoperative radiotherapy in patients with rectal carcinoma: adverse effects during long term follow-up of two randomized trials. Cancer 1996, 78:968-976.

25. Martling A, Holm T, Johansson H, Rutqvist LE, Cedermark B: The Stockholm II trial on preoperative radiotherapy in rectal carcinoma: long-term follow-up of a population-based study. Cancer 2001, 92:896-902.

\section{doi:10.1186/1477-7819-12-355}

Cite this article as: Singh et al:: Rectal cancer surgery in older people does not increase postoperative complications - a retrospective analysis. World Journal of Surgical Oncology 2014 12:355.

\section{Submit your next manuscript to BioMed Central and take full advantage of:}

- Convenient online submission

- Thorough peer review

- No space constraints or color figure charges

- Immediate publication on acceptance

- Inclusion in PubMed, CAS, Scopus and Google Scholar

- Research which is freely available for redistribution

Submit your manuscript at www.biomedcentral.com/submit
C Biomed Central 